\title{
3D PRINTED LARYNGOSCOPE FOR ENDOTRACHEAL INTUBATION
}

\author{
H.W. Huysamen ${ }^{1,2 \# *}$, W.A. Kinnear ${ }^{2}$, T.E. Fonternel ${ }^{3 \dagger}$, E.W. Turton ${ }^{3}$, I. Yadroitsava ${ }^{1} \&$ I. Yadroitsev ${ }^{1 \dagger}$
}

\section{ARTICLE INFO}

\section{Article details}

Presented at the $21^{\text {st }}$ annual international conference of the Rapid Product Development Association of South Africa (RAPDASA), held from 4-6 November 2020.

Available online 11 Nov 2020

\section{Contact details}

Corresponding author HHuysamen@cut.ac.za

\section{Author affiliations}

1 Department of Mechanical and Mechatronic Engineering, Central University of Technology, Free State, South Africa

2 Product Development Technology Station, Central University of Technology, Free State, South Africa

3 Department of Anaesthesiology, University of the Free State, South Africa

\# The author was enrolled for an MEng degree in the Department of Mechanical and Mechatronic Engineering, Central University of Technology, Free State, South Africa

$\dagger \quad$ The author was enrolled for an MMed degree in the Department of Anaesthesiology, University of the Free State, South Africa

\section{ORCID ${ }^{\circledR}$ identifiers}

H.W. Huysamen

https:/orcid.org/0000-0002-9360-0456

W.A. Kinnear

https:/orcid.org/0000-0001-8457-018X

T.E. Fonternel

https://orcid.org/0000-0002-6887-3356

E.W. Turton

https://orcid.org/0000-0001-6916-7691

I. Yadroitsava

https:/orcid.org/0000-0003-3132-5724

l. Yadroitsev

https:/orcid.org/0000-0002-7556-8675

\section{DOI}

http://dx.doi.org/10.7166/31-3-2446
ABSTRACT

This study aims to determine whether additive manufacturing can be used to produce a safe and reliable video laryngoscope. Different designs were proposed and evaluated with a mannequin for usability. Finite element analysis (FEA) was done to estimate the stress distribution, maximum displacement at the tip, and factor of safety. A final 3D printed laryngoscope design was chosen on the basis of this evaluation. Future work on validation, whether it is safe to be used, and the limitations of the device are discussed. The device will be printed under predetermined settings and material to conform to the validation.

\section{OPSOMMING}

Hierdie studie het ten doel om te bepaal of toevoegingsvervaardiging gebruik kan word om ' $n$ veilige en betroubare video-laringoskoop te produseer. Verskillende ontwerpe is voorgestel en geëvalueer met ' $n$ pop vir bruikbaarheid. Eindige element analise is gedoen om die spanningsverspreiding, maksimum verplasing aan die punt en die veiligheidsfaktor te skat. 'n Finale, 3D-gedrukte laringoskoop-ontwerp is gekies op grond van hierdie evaluering. Toekomstige werk aan validering, of dit veilig is om te gebruik, en die beperkings van die toestel word bespreek. Die toestel sal onder voorafbepaalde instellings en materiaal gedruk word om aan die geldigheid te voldoen.

\section{INTRODUCTION}

Additive manufacturing ( $A M)$ is a process in which, as the name suggests, a $3 D$ object is fabricated by adding material to form the object. $A M$ includes a wide variety of methods that use different materials and binding mechanisms. For this research study, the focus will be on entry-level fused deposition modelling (FDM). FDM printers selectively extrude plastic filament in adjacent lines to form a layer. Once the layer is complete, the printer extrudes the same plastic filament onto the previously delivered layer, thus forming an object. The layer-upon-layer AM process allows for the manufacturing of complex geometries and modifying objects between prints if needed.

$A M$ is especially beneficial in the medical field, allowing for patientspecific devices and implants with complex structures to be fabricated relatively more cost-effectively than with other methods [1]. Because of this, 3D printers have been used to produce implants, stents, scaffolds, and other customised devices with individual anatomic features tailored to the patient for successful and safe application [2-5]. When fabricating medical devices and implants, it is of the utmost importance that the material used does not harm or contaminate the patient. 'Biomaterials' refers to natural or synthesised materials that do not react harmfully when coming in contact with human tissues or liquids. Materials that release harmful toxins or materials that the body reject are examples of materials that are not biocompatible. Some materials can also prove beneficial to 
the body; for example, porous materials can promote bone growth and can allow blood to flow freely through the implanted device.

Endotracheal intubation is the placement of a tube into the trachea for airway management with the help of a laryngoscope. This procedure is performed every day on patients who are unconscious and cannot breathe on their own. Laryngoscopy has been the primary method of endotracheal intubation by anaesthesiologist for decades. Video-laryngoscopes, which have an external camera, are very useful: they do not require direct line-of-sight, which greatly improves the ease of intubation. However, they are not cost-effective.

There are currently a few laryngoscopes designs on open-source online platforms but with little or no indication of their manufacturing parameters or instructions for use [6-7]. Mostly the designs of these video laryngoscopes are based on that of the Macintosh laryngoscope (Figure 1a). This is deeply concerning, as these open and freely available products have not been evaluated or certified, which means that they are a potential hazard for patients, and may do more harm than good. Figures $1 \mathrm{~b}$ and $\mathrm{c}$ show an example of such a device. It is essential, therefore, to produce validated medical devices with set instructions for manufacturing and use.

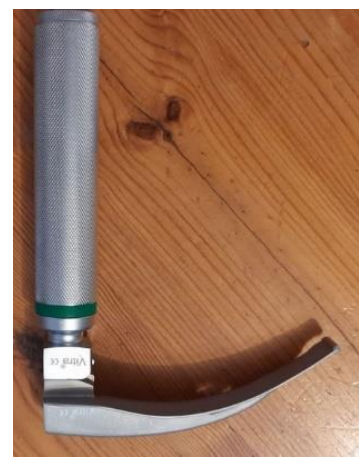

(a)

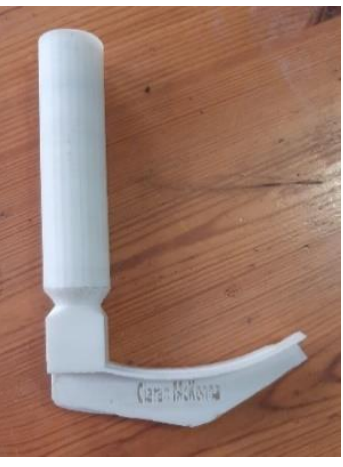

(b)

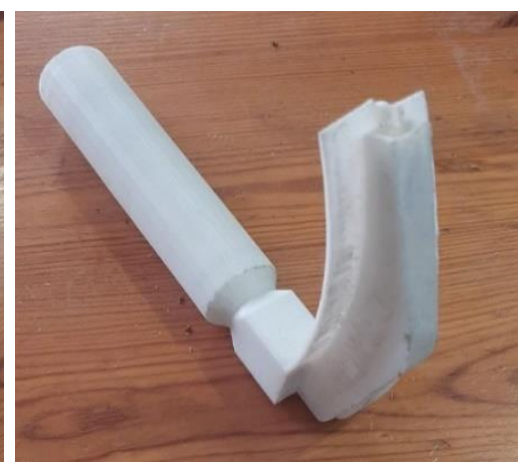

(c)

Figure 1: (a) Macintosh laryngoscope with a number 3 blade, and (b, c) an example of a 3D-printed laryngoscope manufactured on data from open-source online platforms.

'Vamo', a 3D-printed laryngoscope with a hyper-angulated blade, was introduced recently by Papaoum et al. [8]. It was done without any indication of what materials and AM technology were used. A metal 3Dprinted laryngoscope was presented in 2020 by Walker and Macaracaja [9]. It was noted that the designed model improved safety since no stylet was required for intubation as is the standard practice for placing double lumen endotracheal tubes (DLTs). The novel design was able to incorporate the double-lumen tube to be moved inside the blade, so that more space was available for manipulation in the oropharynx.

\section{LARYNGOSCOPE DESIGN}

Successful intubation depends on lifting the hyoid bone with the laryngoscope to provide an open view of the exposed larynx. Two types of laryngoscopes (blades) are used regularly: the Miller straight blade laryngoscope and the Macintosh curved blade [10]. Both have a handle battery holder, blades of different sizes, and a light source. The Macintosh laryngoscope is more commonly used because it creates fewer intubation difficulties and complications by obtaining the optimal angle of the head and neck extensions. The time it takes to complete intubation is kept to a minimum using this blade [11].

\subsection{The design process}

A size 3 Macintosh metal blade was used as a reference for the first designs (Figure 1a). Taking into account that this study will use polymer/plastic material for 3D printing, the computer-aided design (CAD) was modified to be thicker and to have more reinforcement (Figure $2 a$ ). The initial requirements were as follows:

- $\quad$ The model needed space for a camera inside a sleeve at the bottom of the laryngoscope blade.

- The shape of the sleeve would prevent the rotation of the camera in its slot, helping to keep it in the correct orientation when inserted into the laryngoscope. 
The initial design also had a laryngoscope handle connector so that it could be equipped to fit onto a standard laryngoscope handle. After the initial design had been finished and the prototype had been FDMprinted, it was evaluated (Figure 2b). It was found that the space for the light was not needed, as the camera had a built-in light; also, the design needed significant changes, as it had to be designed with AM design rules in mind. This resulted in a more robust design when fabricated in the intended orientation. It was decided to include the handle in the design, thus making it more ergonomic and resulting in easier intubation with this device. Based on reverse-engineering experience with the Macintosh blade, five original designs were suggested, manufactured, and tested (Figure 3).

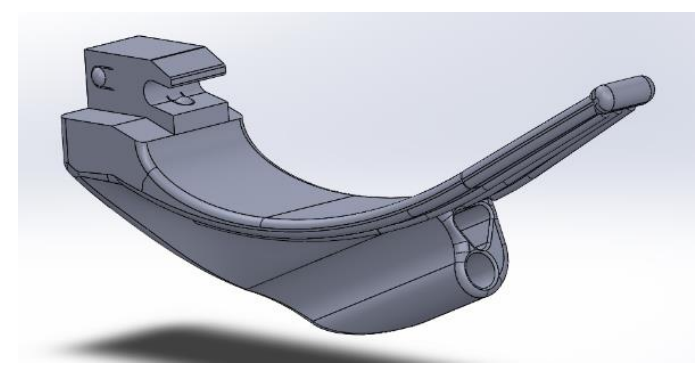

(a)

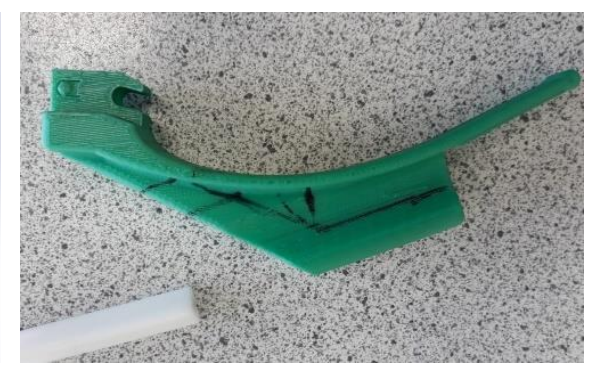

(b)

Figure 2: (a) First CAD design concept, and (b) FDM plastic prototype

In the first design (Figure 3a), a short handle was designed with three-finger grips in front, as it was meant to be held with the index finger to the ring finger in front, the little finger at the bottom back, and the thumb on top of the handle. A primary support profile for a blade has two round support ribs on top separated by a gap, and with a larger round 'spine' at the bottom. The triangular-shaped camera sleeve keeps the camera from rotating, thus keeping the camera's view parallel with the blade.

Figure $3 \mathrm{~b}$ shows the second design with a longer but thinner handle, with two-finger grips in front and a longer back. It was meant to be held with the index and the middle finger in front, the ring and little fingers at the bottom, and the thumb around or on top of the handle. A primary support profile, but with larger round support ribs on the top sides, separated by a gap and a larger round 'spine' at the bottom for more support, was proposed. A rounded shape with one round rib was designed to keep the camera sleeve level.

The third design (Figure $3 c$ ) had a medium bulk handle with three-finger grips in front and a smooth rounded back for more comfortable handling. It was meant to be held with the index finger to the ring finger in front, the little finger at the bottom back, and the thumb on top. The blade profile was a half-circle with rounded corners and a flat top profile for better distribution of the stresses at the bottom. The camera sleeve profile consisted of a main circle for the camera with two rounded side ribs to keep the camera orientated correctly.

Laryngoscope design number four (Figure 3d) had a more extended handle with a broader front, no finger grips, and a lean back with a long smooth curve and a grip for the thumb at the top. It was meant to be held with four fingers in front and the thumb at the top in the clasp. A flattened ' $I$ ' shape was the inspiration for this blade profile with a broader top and a narrow centre. It should be noted that this shape is often used in construction owing to its good strength-to-weight ratio. The sleeve is a circle with a square rib to keep the sleeve in the correct orientation.

In design 5 (Figure 3e), the handle had a small bottom section where it connected to the blade that transitioned to a larger knob at the top for better control and comfort. It was meant to be held with four fingers in front and the thumb at the top or around the knob. A slimmer blade profile with a longer vertical thickness was designed to distribute more of the stress into the material. A circle with two rounded corners and a flat bottom part were used to keep the camera in the correct orientation. 

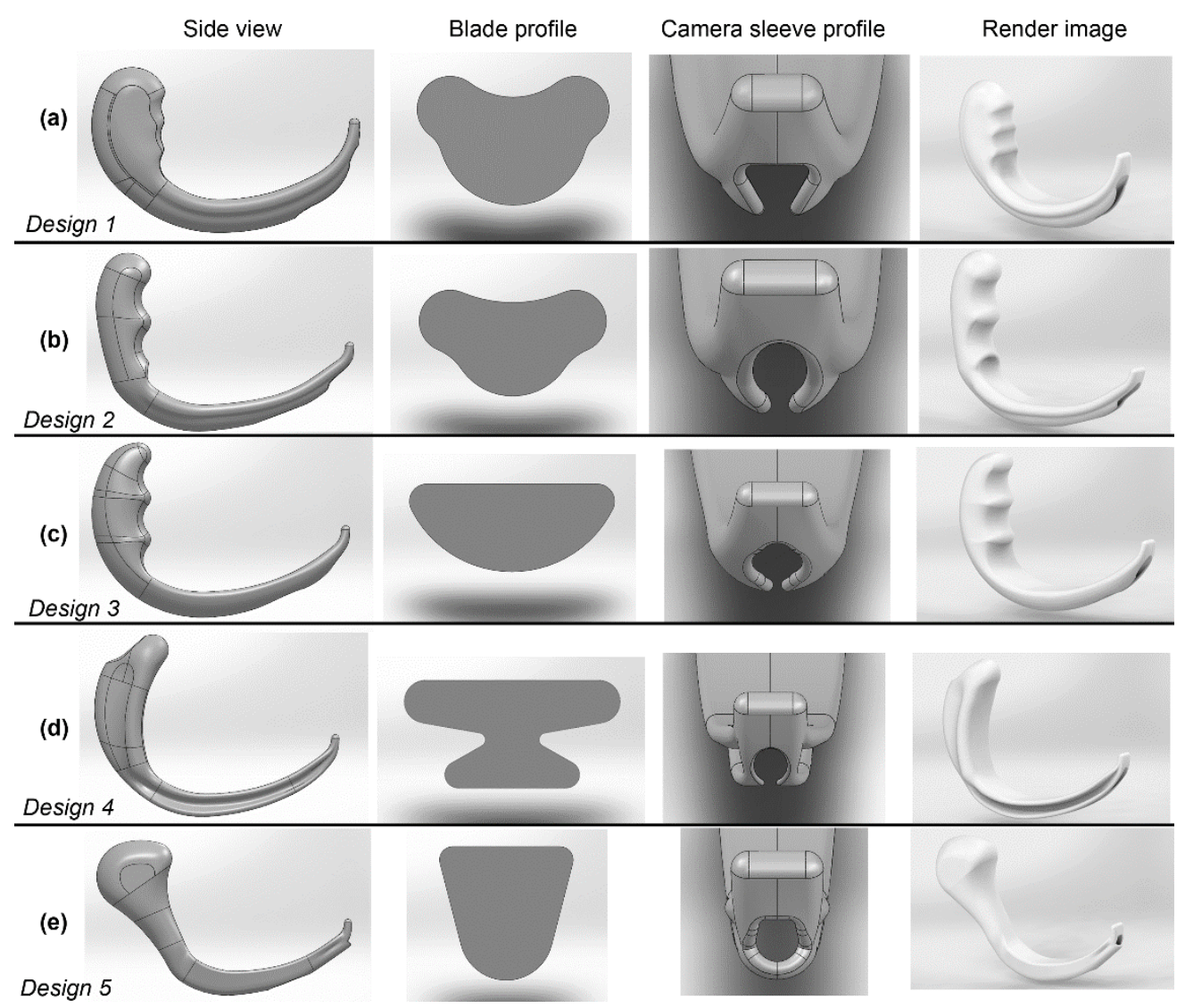

Figure 3: The five different designs

\subsection{Finite element analysis and results}

A finite element analysis (FEA) was performed on the five designs described above to assess their weak points and whether they would be able to handle a sufficient amount of load. The material properties that were used for the simulations are shown in Table 1. According to Russell [12], peak forces of $41 \mathrm{~N}$ on a Macintosh laryngoscope have been found. Rassam et al. [13] tested more than 1000 cases, and showed that the highest force found was $84 \mathrm{~N}$. Hastings et al. [14] did a range of different experiments on the forces exerted on a laryngoscope, and found a peak force of $66 \mathrm{~N}$. Thus, taking into account the most extreme cases, a maximum of $100 \mathrm{~N}$ loading was used in the FEA simulations. The material chosen for the initial FEA simulations was polyethylene terephthalate glycol-modified, more commonly known as 'PETG' (Table 1). PETG is a strong and easily printed material that is food-safe, and so was a promising material to use in this study.

Table 1: The material properties for PETG used for the FEA [153]

\begin{tabular}{|l|c|}
\hline Material properties & Value \\
\hline Elastic modulus & $2.2 \mathrm{GPa}$ \\
\hline Poisson's ratio & 0.33 \\
\hline Shear modulus & $470 \mathrm{MPa}$ \\
\hline Density & $1290 \mathrm{~kg} / \mathrm{m}^{3}$ \\
\hline Tensile strength & $53 \mathrm{MPa}$ \\
\hline Compressive strength & $55 \mathrm{MPa}$ \\
\hline Yield strength & $47.9 \mathrm{MPa}$ \\
\hline
\end{tabular}

Table 2 shows the results obtained from the FEA simulations with the five designs. It was found that that the majority of the designs passed the required load. Design 5 fell just below the required load, and designs 3 and 4 were just above. However, all the designs had peak theoretical forces above that of the worst case of $84 \mathrm{~N}$, found by Rassam et al. [13]. Design 2 proved to be, theoretically, the most promising of the designs. Even though it had the lowest mass and volume (the least amount of material), it withstood the highest stress capabilities. 
Table 2: FEA results

\begin{tabular}{|l|c|c|c|c|c|c|}
\hline Designs & Mass, g & $\begin{array}{c}\text { Volume, } \\
\text { cm }^{3}\end{array}$ & $\begin{array}{c}\text { Max. Von } \\
\text { Mises } \\
\text { stress, MPa }\end{array}$ & $\begin{array}{c}\text { Factor of } \\
\text { safety }\end{array}$ & $\begin{array}{c}\text { Max. } \\
\text { displacement } \\
\text { at the tip, } \\
\text { mm }\end{array}$ & $\begin{array}{c}\text { Theoretical } \\
\text { peak force, } \\
\text { N }\end{array}$ \\
\hline Design 1 & 135 & 104 & 41.6 & $1.2: 1$ & 13.8 & 115 \\
\hline Design 2 & 102 & 79 & 29.0 & $1.7: 1$ & 11.6 & 165 \\
\hline Design 3 & 125 & 97 & 46.4 & $1.0: 1$ & 20.2 & 103 \\
\hline Design 4 & 122 & 95 & 45.6 & $1.1: 1$ & 27.5 & 105 \\
\hline Design 5 & 156 & 121 & 49.7 & $0.96: 1$ & 19.5 & 96 \\
\hline
\end{tabular}

Figure 4 shows the distribution of stress on the different designs. All the designs had been restrained at the handle, similar to a hand holding the laryngoscope. A load of $100 \mathrm{~N}$ was applied vertically downwards on the tips of the designs to obtain the stress diagrams for all the designs. It can be seen that the majority of the stress was distributed at the tops and bottoms of the blades. However, the stresses were concentrated around the sleeve cutaway for all of the designs. This was owing to the material being thinner because of the cutaway, resulting in the force needing to go through thinner walls around the sleeve cutaway.

A 3D-printed material would not be isotropic owing to the layer-by-layer FDM process, and the actual strength would further deviate from the predicted strength as well as the maximum displacement at the tip. FDM parts have lower yield strengths thus they will break at a lower loads than isotropic components; so additional mechanical testing would be done for the final design.

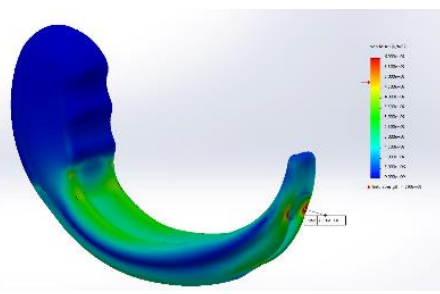

(a)

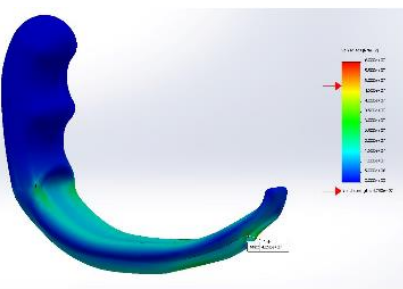

(b)

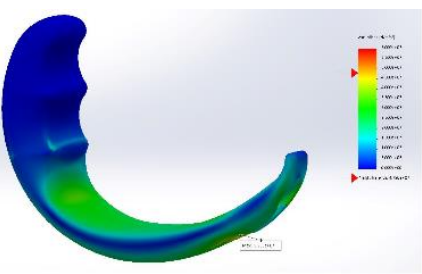

(c)

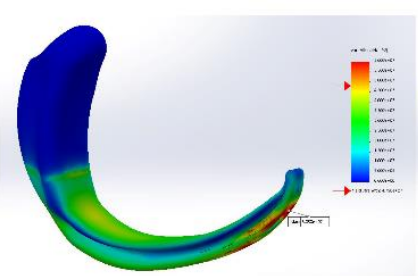

(d)

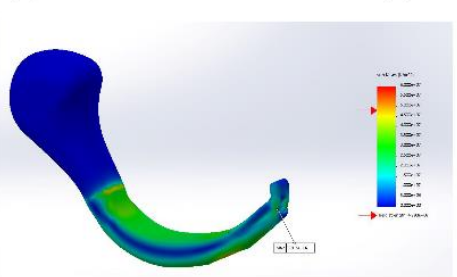

(e)

Figure 4: Von Mises stress distribution at $100 \mathrm{~N}$ loading detected by Finite element analysis (FEA) simulations

\subsection{Mannequin testing and feedback}

The general usability of the laryngoscope prototypes was tested on a Laerdal Airway Management Trainer (Laerdal Medical Corp., USA) by two anaesthesiologists who were part of the design team.

The testing feedback on design 1 showed that the handle was too short (Figure 5). More girth on the handle was needed, along with space for a four-finger grip. Also, the thumb pointed up following the handle, and the handle was too close to the mouth. The blade profile height was adequate, but was too wide to fit the endotracheal tube next to the blade.

The testing of design 2 showed that the handle needed to be wider so that the fingers did not go all the way around in a grasp. The handle also needed to be longer, and it needed an extra grip for another finger. The finger placement was three in front, one at the top, and the thumb pointing upwards in line with the handle. The following improvements were suggested: bigger gaps in the grip, and wider space per finger grip. These changes would be more comfortable and would improve the ease of use. The blade profile height and width were acceptable; however, the handle was too short, bringing the hand too close to the 
mannequin's chin. The shape of the blade where the handle and the blade met seemed to fit the bottom lip of the mannequin quite well, as shown in red in Figure 5, design 2.

For design 3, the handle's width and length could have been increased for improved comfort. In Figure 5 a comparison of the current handle length and the length of the conventional laryngoscope's handle is shown. The positioning of the hand shows that four fingers were in front and the thumb was at the back, pointing up in line with the handle. The grip size and blade profile height were acceptable. However, the blade was too wide to fit the endotracheal tube next to it, and the handle was too short, and therefore too close to the mannequin's mouth.

An analysis of design number 4 showed that the thumb dimple did not work, as it predetermined the location of the hand, which then complicated the hand positioning. People have different hand sizes, and this further affects the hand positioning because of the thumb dimple. The flat grip was not comfortable. The handle was held with four fingers in the front and the thumb around the handle. However, the grip was too small, causing an average-sized hand to wrap completely around the handle, which proved uncomfortable. The length was adequate. The thin rib at the back of the handle contributed to a very uncomfortable grip, as it pressed into the palm. The blade profile height and width were adequate. Notes about the tip of the blade suggested that the right-side gap of the blade be used as a guide for the tube, and that more material be added to the left side of the blade to increase its strength or to use it for the camera cable. Even though this handle was longer, it was still too short, resulting in the hand being too close to the mannequin's mouth.

For design number 5 , the handle felt comfortable in the hand, but needed more material at the bottom to fill the handgrip. The thickness at the top was adequate. Grips for the front four fingers were needed. The device was held with three fingers in front, one at the top front and the thumb over the top, leaning to one side. This was unconventional; however, by reducing the size of the top and increasing the diameter of the bottom part of the handle, this grip could prove to be much more comfortable. The blade length and profile height were adequate. The width was acceptable for placing an endotracheal tube. The hand distance from the mannequin's mouth was acceptable. This design proved to be the most promising, even though it had the highest maximum Von Mises stress and the lowest safety factor of 0.96 (Table 2).
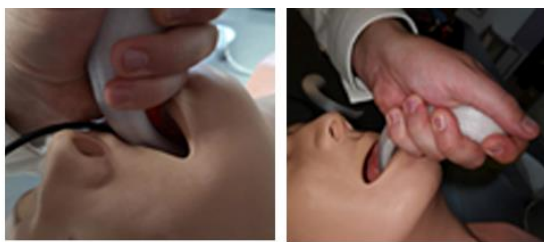

Design 1

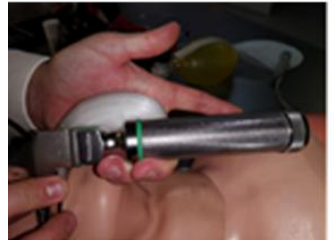

Design 3

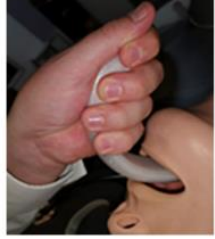

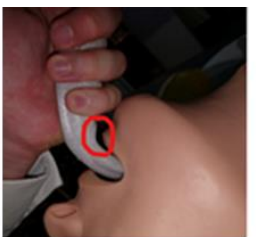

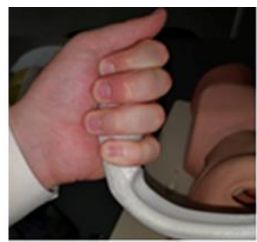

Design 2

Figure 5: Testing procedure of the five designs

\subsection{The final design}

The best features from multiple designs were combined and tested to produce the final design. It consisted of a thinner rounded handle with four finger grips, and a half-circle profile with a cutaway on the righthand side for an endotracheal tube to easily pass by. The sleeve was an oval-shaped cut-away to prevent the sleeve and camera from rotating (Figure 6a). The camera was also offset to the left to make space for the endotracheal tube, and positioned so that the blade did not obstruct the view of the camera, except for a part at the top that assists the user in seeing where the tip of the blade is. 


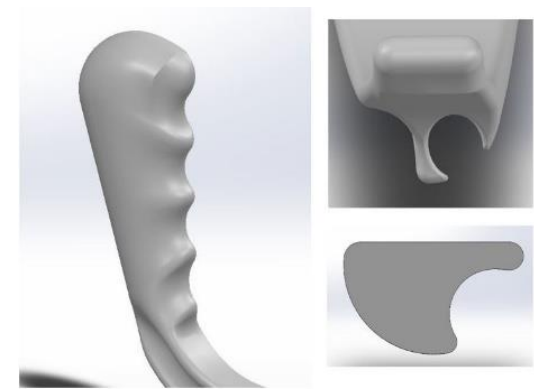

(a)

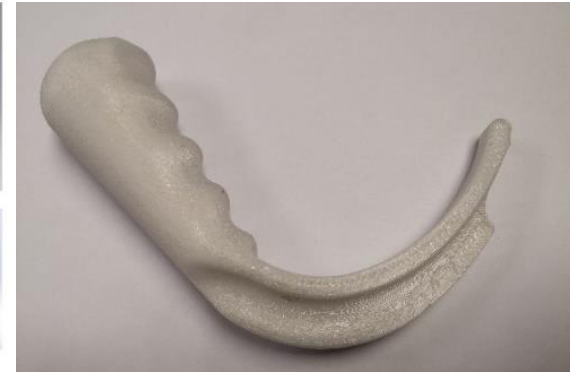

(b)

Figure 6: Final design features (a) and printed laryngoscope (b)

The final design was FDM-printed on its side with the endotracheal tube cutaway facing up. Special supports were needed for the print, but they were easily removed. Figure $6 \mathrm{~b}$ shows the printed laryngoscope. In early testing, the final design was promising: the handle was found to be comfortable; the blade could be manoeuvred with ease; and the endotracheal tube could easily pass by the laryngoscope, making intubation of the mannequin possible. Larger-scale testing will be conducted in a later stage of the study. Figure 7 shows some early clinical simulation testing performed with the final design, and Figure 8 shows the view from the camera attached to the laryngoscope.
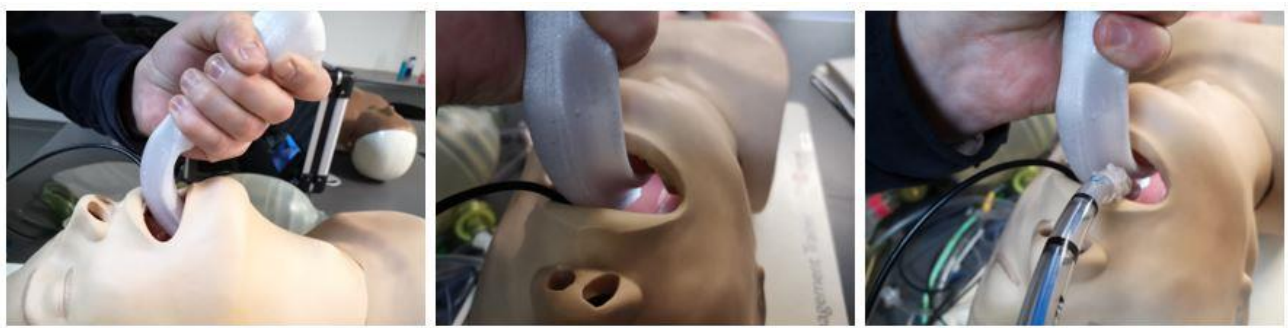

Figure 7: The final design's initial tests

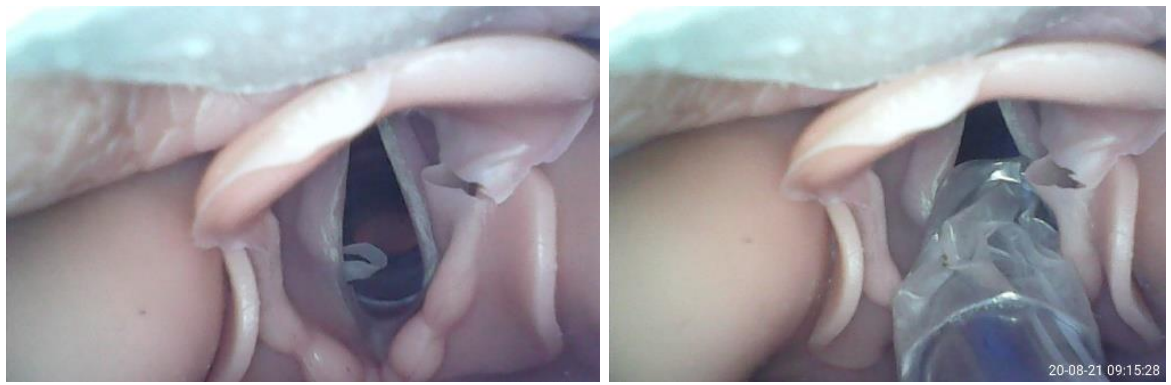

Figure 8: The view from the laryngoscope camera

\section{3}

\section{USABILITY STUDY}

\subsection{Material and equipment selection}

The next stage of the study was the selection of the material. It had to be non-toxic to a human body, biocompatible, and sterilisable; it had to have enough strength; and it had to offer good printability and be at a reasonable price. Since plastic material is quite sensitive to heat, low-temperature sterilisation was used. Based on these criteria, materials for FDM printers were evaluated and ranked: Copper3D PLActive; 3D4MAKERS Facilan HT; 3D4MAKERS PLA; 3D4MAKERS PETG; CCTREE polypropylene; CRON PETG; ESUN ePEEK; ESUN HIPS; and ESUN NYLON EPA. A similar procedure - based on build size, maximum temperature, printing speed, accuracy, and price - was carried out to select the FDM printer. 


\subsection{D-printed specimen testing}

The selected material would have to undergo bending tests to obtain an accurate reading of the mechanical property of the material after it had been fabricated. Tensile and bending tests would also have to be done on specimens that had been sterilised to observe how the material had degraded.

The first 10 to 20 test specimens were FDM 3D printed from the same roll of filament and the same material and supplier to finalise the design procedure. This ensured consistency when obtaining the data. The test specimens underwent mechanical testing to obtain accurate property values and to validate the FEA. Another set of 10 to 20 specimens was printed from the same roll of filament and on the same printer as the previous set. This set was then sterilised and dried, after which it also underwent tensile and bending testing to observe the material degradation as a result of the sterilisation. Multiple tests could be done with more sets of 10 to 20 specimens with different techniques of sterilisation to find the best option that degrades the material the least. To date, low temperature testing appears to be more applicable to plastic medical devices.

\subsection{Analysis of quality and reliability}

The quality and reliability of the selected FDM 3D printer had to be proved to validate the printer. This was tested by fabricating 'test' models that revealed the limitations of the printer (overhangs, surface quality, phantom shacking, excess material on the nozzle, etc.). This test was done multiple times to determine the optimal printing parameters of the selected material on the selected printer.

Once the optimal parameters had been selected, the reliability and quality of the printers could be tested. This was done by fabricating multiples of the prototype laryngoscope to observe the consistency of the surface quality and the failure rate of the fabrication. If a recurring failure occurred, the parameters were modified or the bed adhesion was changed until the printer's reliability could be confirmed.

The data collected from the specimen mechanical testing was then used in FEA so that the design could be numerically simulated to test the theoretical maximum load of the device. The finalised design was then fabricated on the selected parameters multiple times and underwent tensile testing on the device's points of load (the tip of the blade). The mechanical test data was then compared with the FEA data to validate the design and fabrication process further.

\subsection{Testing usability of the FDM-printed laryngoscope by end-users}

A randomised crossover study will be done in the Anaesthesiology Department at the Free State University with around 40 participants. The participants will include consultants, registrars, and medical officers working in the department when the study is initiated. The participants will use the FDM-printed video laryngoscope to intubate a mannequin.

The usability of the FDM-printed video laryngoscope will be compared with the usability of the currently well-known C-MAC ${ }^{8}$ video laryngoscope with its D-blade. The criteria of usability will be:

- The time in seconds to vocal cord visualisation.

- $\quad$ The time in seconds to the first pass of the endotracheal tube.

- $\quad$ The quality of the laryngeal view using the Cormack-Lehane score.

- Successful intubation.

\section{CONCLUSION}

This study aimed to determine whether additive manufacturing - in particular, the FDM method - could be used to produce a safe and usable video laryngoscope. A step-by-step process for validation procedure was done: 1) design development, taking into account the peculiarities of the 3D-printing process, 2) earlystage testing for usability and handling by end-users; 3) approving the final design; 4) ranking the required material and equipment.

Further studies will choose the building strategy for a 3D-printed laryngoscope, including its optimisation process parameters, roughness analysis, and mechanical testing, as well as the influence of sterilisation on samples' lifespan. A test of the usability of the FDM-printed laryngoscope will be done by medical doctors.

In conclusion, the results obtained to date indicate great potential for the successful completion of a multidisciplinary project between medical doctors and engineers. Manufacturing a 3D-printed laryngoscope 
could have a significant impact on the availability and cost of video laryngoscopes; and more lives could be saved using this technology.

\section{RESEARCH ETHICS APPROVAL}

This study was conducted in adherence with the current version of the Declaration of Helsinki and GCP guidelines. The initial research project was approved by the ethics committee of the Faculty of Health Sciences at University of the Free State: Ethics number UFS-HSD2019/1980/2605, dated 11 May 2020.

\section{ACKNOWLEDGEMENTS}

This work is based on research supported by a multi-, inter- and trans- (MIT) disciplinary collaborative research grant of the Central University of Technology and the University of the Free State (Sixth CUT \& UFS Joint Research Programme 2020-2021), as well as the South African Research Chairs Initiative of the Department of Science and Technology, National Research Foundation of South Africa (Grant No. 97994).

\section{REFERENCES}

[1] Durfee, W.K. \& laizzo, P.A. 2018. Medical applications of 3D printing. In Engineering in medicine: Advances and challenges, Academic Press, London. pp. 527-543.

[2] Putnam, K. 2016. Customizing surgical care with 3D printing. AORN Journal, 103(6), pp. 13-14.

[3] Alraiyes, A.H., Avasarala, S.K., Machuzak, M.S. \& Gildea, T.R. 2019. 3D printing for airway disease. AME Medical Journal, North America, 4. Available: http://amj.amegroups.com/article/view/4829 [Accessed: 30-Aug-2020]

[4] Gildea, T.R., Young, B.P. \& Machuzak, M.S. 2018. Application of 3D printing for patient-specific silicone stents: 1-year follow-up on 2 patients. Respiration, 96(5), pp. 488-494.

[5] Stramiello, J.A., Saddawi-Konefka, R., Ryan, J. \& Brigger, M.T. 2020. The role of 3D printing in pediatric airway obstruction: A systematic review. International Journal of Pediatric Otorhinolaryngology. 132, pp.109923 (1-7).

[6] Triantopoulos, A., Triantopoulos, O., Kostopoulos, V., Dimitrakopoulou, K., Spyraki, M. \& Papanaoum, M. 2020. Presenting an innovative 3D-printed video laryngoscope. Trends in Anaesthesia and Critical Care, 30, pp. e1ee192.

[7] MakerBot Thingiverse. 2017. Printable video laryngoscope shell by dokcmk. Available: https: / /www.thingiverse.com/thing:2515572 [Accessed: 30-Aug-2020].

[8] Papanaoum, M., Triantopoulos, A., Triantopoulos, O., Kostopoulos, V., Dimakopoulos, K. \& Triantopoulos, G. 2018. 'Vamo': Introducing a low-cost reusable 3D printed video laryngoscope. Trends in Anaesthesia and Critical Care, 23, pp. 21-22.

[9] Walker, C.A. \& Maracaja, L. 2020. The use of 3D-printing for the creation and development of novel tools to facilitate cardiothoracic anesthesiology. Journal of Cardiothoracic and Vascular Anesthesia, 34(4), pp. $302-303$.

[10] Marks, R.R., Hancock, R. \& Charters, P. 1993. An analysis of laryngoscope blade shape and design: New criteria for laryngoscope evaluation. Canadian Journal of Anesthesia, 40(3), pp. 262-270.

[11] Frohlich, S., Borovickova, L., Foley, E. \& O'Sullivan, E. 2011 A comparison of tracheal intubation using the McGrath or the Macintosh laryngoscopes in routine airway management. European Journal of Anaesthesiology, 28(6), pp. 465-467.

[12] Russell, T., Khan, S., Elman, J., Katznelson, R. \& Cooper, R.M. 2012. Measurement of forces applied during Macintosh direct laryngoscopy compared with GlideScope ${ }^{\circledR}$ videolaryngoscopy. Anaesthesia, 67(6), pp. 626-631.

[13] Rassam, S., Wilkes, A.R., Hall, J.E. \& Mecklenburgh, J.S. 2005. A comparison of 20 laryngoscope blades using an intubating manikin: Visual analogue scores and forces exerted during laryngoscopy. Anaesthesia, 60(4), pp. 384394.

[14] Hastings, R.H., Hon, E.D., Nghiem, C. \& Wahrenbrock, E.A. 1996. Force and torque vary between laryngoscopists and laryngoscope blades. Anesthesia \& Analgesia, 82(3), pp. 462-468.

[15] 3D4Makers.com. 2020. TDS PETG filament. Available: https://cdn.shopify.com/s/files/1/0762/2839/files/TDS_PETG_Filament.pdf [Accessed 1-Sep-2020]. 